\title{
CRESCIMENTO DE CULTIVARES DE MAMONEIRA EM FUNÇÃO DA APLICAÇÃO DE BORO, DURANTE A FORMAÇÃO DE MUDAS
}

\section{GROWTH TO CULTIVATE OF CASTOR BEAN WITH APLICATION OF BORON, DURING THE FORMATION OF CHANGES}

\author{
Helen Cristina de Arruda RODRIGUES ${ }^{1}$ \\ Samuel Pereira de CARVALHO ${ }^{2}$ \\ Henrique Antunes de SOUZA ${ }^{3}$ \\ Adriana Madeira Santos JESUS ${ }^{4}$
}

\begin{abstract}
RESUMO
Objetivou-se quantificar o crescimento inicial de variedades de mamoneiras adubadas com boro. Foram testadas as cultivares AL-Guarani, Mirante 10 e Nordestina submetidas às doses de $0 ; 0,25 ; 0,50 ; 0,75$ e $1,0 \mathrm{mg} \mathrm{kg}^{-1}$ de $B$ em ambiente controlado de casa-de-vegetação no Setor de Cafeicultura do Departamento de Agricultura da UFLA. Foram avaliadas as características de altura de plantas, comprimento de raízes, número de folhas, diâmetro de caule, massa de matéria seca (MS) das folhas (pecíolo + limbo), do caule, da raiz e total. A cultivar Mirante 10 foi a que obteve menor crescimento do sistema radicular. Para número de folhas a cultivar AL-Guarani foi superior à Mirante 10 e Nordestina. Também a cultivar AL-Guarani melhor se destacou quanto à produção de massa de MS total, enquanto a cultivar Mirante 10 produziu mais massa de MS comparada à cultivar Nordestina.
\end{abstract}

Palavras-chave: Ricinus communis L.; casa de vegetação; adubação.

\section{ABSTRACT}

It was objectified to quantify the initial growth of varieties of castor bean with boron fertilization. Had been tested to cultivate they AL-Guarani, Mirante 10 and Nordestina to the doses of $0 ; 0.25 ; 0.50 ; 0.75$ and $1.0 \mathrm{mg} \mathrm{kg}^{-1}$ of $B$ in controlled environment of greenhouse in the Sector of Cafeicultura of the Department of Agriculture of the UFLA. The characteristics valued were: height of plants, length of roots, leaf number, diameter of stem, mass of dry substance (MS) of leafs, of stem, the root and total. To cultivate Mirante 10 it was the one that got minor growth of the system of root. For leaf number to cultivate AL-Guarani it was superior to Mirante 10 and Nordestina. Also to cultivate better AL-Guarani if it detached how much to the production of total mass of MS, while to cultivate Mirante 10 produced more mass of MS than Nordestina.

Key-words: Ricinus communis L.; greenhouse; fertilization.

\footnotetext{
${ }^{1}$ Eng ${ }^{a}$. Agrônoma, Doutoranda, Departamento de Tecnologia, Faculdade de Ciências Agrárias e Veterinárias (FCAV), Universidade Estadual Paulista "Júlio de Mesquita Filho" (UNESP), Via de Acesso Prof. Paulo Donato Castellane, s/n, CEP: 14884-900, Jaboticabal-SP, Brasil. Email: helenarruda11@gmail.com

${ }^{2}$ Eng $^{\circ}$. Agrônomo, Dr., Professor, Departamento de Agricultura, Universidade Federal de Lavras (UFLA), C.P: 3037, CEP:37200-000, Lavras-MG, Brasil. E-mail: samuelpc@ufla.br

${ }^{3}$ Eng $^{\circ}$.Agrônomo, Doutorando, Departamento de Solos e Adubos, Faculdade de Ciências Agrárias e Veterinárias (FCAV), Universidade Estadual Paulista "Júlio de Mesquita Filho" (UNESP), Via de Acessso Prof. Paulo Donato Castellane, s/n, Zona Rural, CEP: 14884-900, Jaboticabal-SP, Brasil. E-mail: henrique.antuness@yahoo.com.br (autor para correspondência)

${ }^{4}$ Eng $^{\mathrm{a}}$. Agrônoma, Pesquisador, Dr., Empresa de Pesquisa Agropecuária de Minas Gerais (EPAMIG), Universidade Federal de Lavras, Caixa Postal 3037, CEP: 37200-000, Lavras-MG, Brasil. E-mail: madeiradri@gmail.com.
} 
RODRIGUES, H.C.A. et al. Crescimento de cultivares de mamoneira...

\section{INTRODUÇÃO}

A mamoneira (Ricinus communis L.) é originária do continente africano e introduzida no Brasil pelos colonizadores portugueses. A extraordinária adaptação da planta e as múltiplas aplicações de seu óleo potencializaram cultivos em quase todos os locais do país, sendo Bahia, Paraná, São Paulo, Ceará e Pernambuco os principais produtores (Melhorança et al., 2005).

A baga da mamona é uma fonte de ácido ricinoléico, que, além da ampla gama de aplicação industrial, e também uma alternativa de combustível, que repercuti-se como importante base econômica e estratégica do país (Savy Filho \& Banzato, 1987).

No Brasil a produtividade da mamoneira é de $1.000 \mathrm{~kg} \mathrm{ha-1}$, sendo considerada baixa (Melhorança et al., 2005). Segundo Beltrão et al. (2002) as áreas cultivadas com mamona ampliaram para o Cerrado das Regiões Nordeste e CentroOeste, visando principalmente à produção do biodiesel.

A adubação é uma das práticas culturais mais importantes para mamoneira dada às elevadas concentrações minerais acumuladas na planta, porém, é pouco estudada no Brasil (Melhorança et al., 2005). A deficiência de boro é uma das mais comuns no País, relatada em diversas culturas. Essa carência pode ser ocasionada por diversos fatores, estando diretamente relacionada ao tipo de solo, às dificuldades de manejo desse nutriente, principalmente associado com possíveis toxidezes quando de doses pouco acima das exigidas pelas culturas (Haddad \& Kaldor, 1982). Kappes et al. (2008) estudando doses e épocas de aplicação de boro na qualidade de sementes de soja, observaram que a não aplicação de boro não prejudicou a qualidade fisiológica, porém estas não atingiram o potencial necessário a comercialização.

Segundo Santos et al. (2004), o boro é um importante micronutriente requerido para o desenvolvimento e produção de plantas, sendo que sua deficiência reduz normalmente o tamanho do sistema radicular e causa a morte de tecidos meristemáticos. O retardamento do crescimento dos ápices das raízes durante o período vegetativo está relacionado à função do boro na parede celular (Matoh, 1997).

Foi realizado estudo para avaliar o desenvolvimento e os efeitos ultra-estruturais de deficiência e toxicidade de boro em mamoneira (Silva et al., 2008). Foram observados os efeitos morfológicos e as alterações na ultra-estrutura celular nas folhas e pecíolos, através da técnica de microscopia eletrônica de transmissão e varredura, a produção de matéria seca da mamoneira foi afetada em condições de deficiência de boro, mas não em condições de toxicidade $\left(5,4 \mathrm{mg} \mathrm{dm}^{-3} \mathrm{~B}\right)$; na omissão de boro, as plantas apresentaram deformação de folhas novas, morte do meristema apical, engrossamento da lamela média, ausência de grânulos de amido nos cloroplastos e desorganização dos vasos condutores do pecíolo; o desenvolvimento e a produção da mamoneira são afetados em condições de deficiência de boro mas não na condição de toxicidade.

Para Silva et al. (2007) as cultivares que estão sendo utilizadas por agricultores e órgãos de pesquisa são introduzidas dos programas de melhoramento da CATI/SP, Embrapa Algodão, IAC/ SP e Sementes Armani S/A; cita-se a Mirante 10 que é uma variedade de mamona, lançada por Sementes Armani; apresenta frutos indeiscentes, porte médio e ciclo médio, haste vermelha, sem cera; apresenta também bom potencial de rendimento. A Nordestina lançada em 1998 pela Embrapa Algodão foi obtida por meio de seleção individual com testes de progênie da variedade local Baianita; apresenta porte médio e frutos semideiscentes. A cultivar AL Guarani 2002 foi lançada em 2002 pelo Departamento de Sementes, Mudas e Matrizes da Coordenadoria de Assistência Técnica Integral (CATI); originada por seleção massal clássica da cultivar Guarani, a qual provém de multiplicação própria realizada por várias gerações de agricultores; apresenta ciclo de 180 dias (até a colheita dos cachos terciários), porte médio, fruto indeiscente, coloração das hastes roxaavermelhada com cerosidade e ramificações com angulação bem fechada.

As sementes de mamona apresentam grande variação de tamanho e densidade, dificultando a regulagem de semeadoras e a uniformidade na emergência das plantas, resultando em populações desiguais que levam a baixa produtividade. Elas ainda possuem dormência, que associada à baixa qualidade fisiológica das sementes disponíveis no mercado, incluindo-se aí até as sementes classificadas como sementes básicas, diminui a germinação com variável vigor das plântulas (Shepentina \& Sevast'Yanova, 1986). Assim, utilizar mudas, substituindo a semeadura direta, pode se justificar pelo maior "pegamento", pela uniformidade de estande populacional e maior desenvolvimento nos estágios iniciais da cultura no campo.

Para produção de mudas de mamona ainda não se dispõe de muitas informações técnicas sobre adubação recomendada. Devido isto, o objetivo do trabalho foi avaliar o crescimento em mudas e cultivares de mamoneira adubadas com boro.

\section{MATERIAL E MÉTODOS}

O experimento foi conduzido em casa-devegetação no Setor de Cafeicultura do Departamento de Agricultura da UFLA, Lavras, MG. Utilizou-se sacolas plásticas com capacidade de 3 $\mathrm{dm}^{3}$, e como substrato foi usado o Plantmax-café ${ }^{\circledR}$. Segundo Miranda et al. (1998) a composição mineral média desse substrato compreendida por cascas de pinus processadas e enriquecidas, vermiculita expandida, parlita e turfa processada e enriquecida é $\mathrm{pH}$ [água] - 4,7; M.O. (matéria orgânica) - $578 \mathrm{~g} \mathrm{~kg}^{-1}$; C.O. (carbono orgânico)- 
RODRIGUES, H.C.A. et al. Crescimento de cultivares de mamoneira...

$321 \mathrm{~g} \mathrm{~kg}^{-1} ; \mathrm{N}-8,12 \mathrm{~g} \mathrm{~kg}^{-1} ; \mathrm{P}-2,81 \mathrm{~g} \mathrm{~kg}^{-1} ; \mathrm{K}-4,80$ $\mathrm{g} \mathrm{kg}^{-1}$; RMT (resíduos minerais totais) $-422 \mathrm{~g} \mathrm{~kg}^{-1}$; umidade à $65{ }^{\circ} \mathrm{C}-67,22 \mathrm{dag} \mathrm{dm}^{-3}$; condutividade elétrica $-3,33 \mathrm{dS} \mathrm{m}^{-1}$.

As sementes foram semeadas em bandejas com areia até a protusão da radícula (aproximadamente 5 dias) e depois transplantadas para o recipiente com o substrato. Os tratamentos consistiram de 5 doses de B e 3 cultivares - ALGuarani, Mirante 10 e Nordestina - sendo um fatorial $5 \times 3$, com 3 repetições e 2 plantas por parcela, perfazendo um total de 90 plantas. As doses de boro foram adaptadas segundo recomendação de Malavolta (1981) para adubação em vasos. O delineamento experimental foi em blocos ao acaso.

As doses consistiram de $0 ; 0,25 ; 0,50 ; 0,75$ e $1,0 \mathrm{mg} \mathrm{kg}^{-1}$ de $B$ no substrato, sendo a dose de $0,5 \mathrm{mg} \mathrm{kg}^{-1}$ uma referência proposta por Malavolta (1981), utilizando como fonte o ácido bórico. As aplicações iniciaram quando as plantas apresentaram o primeiro par de folhas verdadeiras, e foi realizado via fertirrigação $\left(50 \mathrm{~cm}^{3}\right.$ por recipiente), durante 40 dias, sendo 3 aplicações semanais. A cada 10 dias foram aplicados $30 \mathrm{mg}$ de uréia, $198 \mathrm{mg}$ de superfosfato simples, $23 \mathrm{mg}$ de $\mathrm{KCl}$ e $0,21 \mathrm{mg}$ de sulfato de zinco, comum a todos os tratamentos (via solução), com base na recomendação de Malavolta (1981) para experimentos com vasos. Utilizou-se nos recipientes $3 \mathrm{dm}^{3}$ de substrato por sacola; a irrigação do experimento foi realizada diariamente e a umidade relativa (UR) foi mantida em torno de
$85 \%$ (casa de vegetação).

As variáveis avaliadas foram: altura de plantas, comprimento de raízes, número de folhas, diâmetro de caule, matéria seca das folhas (pecíolo + limbo), matéria seca do caule, matéria seca de raiz e matéria seca total.

Para altura das plantas foi medido do colo até o ápice com régua graduada em centímetros, para comprimento de raízes estas foram esticadas e medidas até a extremidade utilizando-se também régua graduada em centímetros, para número de folhas foram contadas todas as presentes nas mudas, para diâmetro de caule foi coletado o valor entre 5 a $7 \mathrm{~cm}$ do colo utilizando-se paquímetro e, para a massa de matéria seca das plantas foram colocadas em estufa de ventilação forçada de ar, a uma temperatura entre 65 a $70{ }^{\circ} \mathrm{C}$, até atingir massa constante.

As variáveis foram analisadas e realizado o desdobramento de regressão e teste de médias segundo sua significância.

\section{RESULTADOS E DISCUSSÃO}

Todas as características de crescimento estudadas não foram influenciadas significativamente pela interação doses de $B$ e cultivares de mamoneira (Tabela 1). As variáveis biométricas comprimento de raiz, diâmetro e número de folhas foram afetadas pelas cultivares (Tabela 2), incluindo os dados de MS de caule e folha. Para comprimento da parte aérea, MS de raiz e total além de cultivares também ocorreu resposta significativa às doses de $\mathrm{B}$.

TABELA 1 - Resumo da análise de variância para comprimento de parte aérea (CPA), comprimento de raiz (CRA), número de folhas (NF), diâmetro (DIA), matéria seca de raiz (MSR), matéria seca de caule (MSC), matéria seca de folha (MSF) e matéria seca total (MST) de mudas de mamoneiras. UFLA, Lavras, 2008.

\begin{tabular}{lcccccccc}
\hline & & \multicolumn{9}{c}{ Quadrado médio } & & \\
& CPA & CRA & NF & DIA & MSR & MSC & MSF & MST \\
\hline Doses de B (DB) & $13,52^{*}$ & $6,93^{\text {NS }}$ & $0,21^{\text {NS }}$ & $0,01^{\text {NS }}$ & $0,14^{* *}$ & $0,01^{\text {NS }}$ & $0,02^{\text {NS }}$ & $0,28^{* *}$ \\
Cultivares (CULT) & $43,35^{* *}$ & $66,28^{* *}$ & $3,11^{* *}$ & $0,05^{* *}$ & $0,38^{* *}$ & $0,02^{* *}$ & $0,09^{* *}$ & $1,03^{* *}$ \\
DB CULT & $3,01^{\text {NS }}$ & $9,91^{\text {NS }}$ & 0,11 NS & $0,01^{\text {NS }}$ & $0,03^{\text {NS }}$ & $0,01^{\text {NS }}$ & $0,01^{\text {NS }}$ & $0,06^{\text {NS }}$ \\
\hline CV $(\%)$ & 9,1 & 20,4 & 5,4 & 7,2 & 26,3 & 13,7 & 12,2 & 11,7 \\
\hline
\end{tabular}

NS, * $e^{* *}$ - Não significativo pelo teste de F, significativo a $5 \%$ e $1 \%$

TABELA 2 - Resultados de três cultivares de mamona na produção de mudas: comprimento da parte aérea $(\mathrm{cm})(\mathrm{CPA})$, comprimento de raiz $(\mathrm{cm})(\mathrm{CRA})$, diâmetro do caule $(\mathrm{mm})$ (DIA), número de folhas por planta (NF), matéria seca do caule por planta (g) (MSC), matéria seca da raiz por planta $(\mathrm{g})$ (MSR), matéria seca da folha por planta (g) (MSF), total por planta (g) (MST). UFLA, Lavras, 2008.

\begin{tabular}{|c|c|c|c|c|c|c|c|c|}
\hline Cultivar & CPA & CRA & DIA & NF & MSC & MSR & MSF & MST \\
\hline & \multicolumn{2}{|c|}{--------- cm ----------- } & $\mathrm{mm}$ & & \multicolumn{4}{|c|}{ 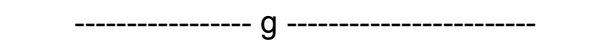 } \\
\hline Nordestina & $24,45 a^{*}$ & $15,28 \mathrm{a}$ & $0,42 \mathrm{c}$ & $5,86 \mathrm{~b}$ & $0,34 \mathrm{~b}$ & $0,33 \mathrm{~b}$ & $0,79 \mathrm{~b}$ & $1,46 \mathrm{c}$ \\
\hline Mirante 10 & 25,79 a & $11,13 b$ & $0,47 \mathrm{~b}$ & $5,96 \mathrm{~b}$ & 0,39 a & $0,55 a$ & $0,78 \mathrm{~b}$ & $1,72 b$ \\
\hline AL-Guarani & $22,41 b$ & $13,82 \mathrm{a}$ & $0,54 a$ & 6,70 a & $0,42 \mathrm{a}$ & $0,64 \mathrm{a}$ & $0,93 a$ & $1,99 \mathrm{a}$ \\
\hline
\end{tabular}

* Médias seguidas pela mesma letra na coluna não diferem estatisticamente entre si a $5 \%$ pelo teste de Scott-Knott 
RODRIGUES, H.C.A. et al. Crescimento de cultivares de mamoneira...

As cultivares Nordestina e Mirante 10 obtiveram maior crescimento em relação à $A L-$ Guarani, ocorrendo menor crescimento radicular na cultivar Mirante 10 (Tabela 2). Kappes et al. (2008) testando doses de B na cultura da soja, verificaram efeito significativo do nutriente fornecido via foliar.

O número de folhas e a massa de MS de folhas na cultivar AL-Guarani foi superior à Mirante 10 e Nordestina; ocorrendo semelhante comportamento para os dados de massa de MS de caule e raízes (Tabela 2). Para diâmetro e massa de MS total a cultivar AL-Guarani foi superior à Mirante 10 e Nordestina. Silva et al. (2005) avaliando germinação e crescimento inicial de mamoneiras submetidas ao estresse salino observaram que a cultivar CSRN-367 foi melhor adaptada comparada à cultivar Paraguaçu.

A cultivar AL-Guarani apresentou superioridade para comprimento de raiz juntamente com a Nordestina (Tabela 2); para diâmetro, número de folhas, massa de MS de folha e total a AL-Guarani foi superior as demais mamoneiras. Já para massa de MS de caule a Nordestina teve menor incremento em relação às outras duas cultivares.

Para comprimento da parte aérea as mudas da Mirante 10 e Nordestina foram superiores a AL-Guarani (Tabela 2), exceto para comprimento da parte aérea a sua menor altura (AL-Guarani) tenha sido compensada pelo seu maior diâmetro, proporcionando maior massa de MS do caule e consequentemente sua massa total (da matéria seca).

A cultivar Mirante 10 apresentou maior massa de MS total que a cultivar Nordestina, sendo também em conseqüência do seu maior diâmetro, como também ter maior massa em relação à MS de raiz. Apesar da cultivar Nordestina ter apresentado maior comprimento de parte aérea e raiz tal crescimento não se pronunciou para massa da MS, em que obteve o pior desempenho.

Gomes et al. (2002) verificaram que dentre as características morfológicas de mudas de Eucalyptus grandis, a altura e a relação altura/ massa de MS da parte aérea devem ser consideradas, pelo fato de apresentarem boa contribuição relativa ao padrão de qualidade das mudas. Na cultivar Nordestina, a relação altura/ massa de MS da parte aérea foi de 21,4; Mirante 10 de 22,04 e da AL-Guarani de 16,6. Os referidos autores mencionam que estimar a qualidade das mudas mediante avaliação da altura destas é interessante, pois constitui um procedimento não destrutivo.

O comprimento da parte aérea apresentou uma resposta linear negativa às doses de B (Figura 1). Os dados de massa de MS radicular responderam de forma quadrática às doses de $B$, estimando-se máximo valor de $0,60 \mathrm{~g}$ raiz $^{-1}$ ao se aplicar $0,36 \mathrm{mg} \mathrm{kg}^{-1}$ de $B$ (Figura 2). Corrêa et al. (2006) verificaram que aplicações iguais ou superiores a $6 \mathrm{mg} \mathrm{dm}^{-3}$ de $\mathrm{B}$ prejudicam a produção de massa de MS de parte aérea e de raiz em rizicultura.

A MS total apresentou resposta quadrática às doses de $\mathrm{B}$ e similarmente à MS de raiz atingiu máximo valor ao se aplicar $0,36 \mathrm{mg} \mathrm{kg}^{-}$ ${ }^{1}$ de $B$ (Figura 3 ). O resultado indica que doses acima de $0,36 \mathrm{mg} \mathrm{kg}^{-1}$ de boro é prejudicial à produção de massa de MS de mudas de mamona.

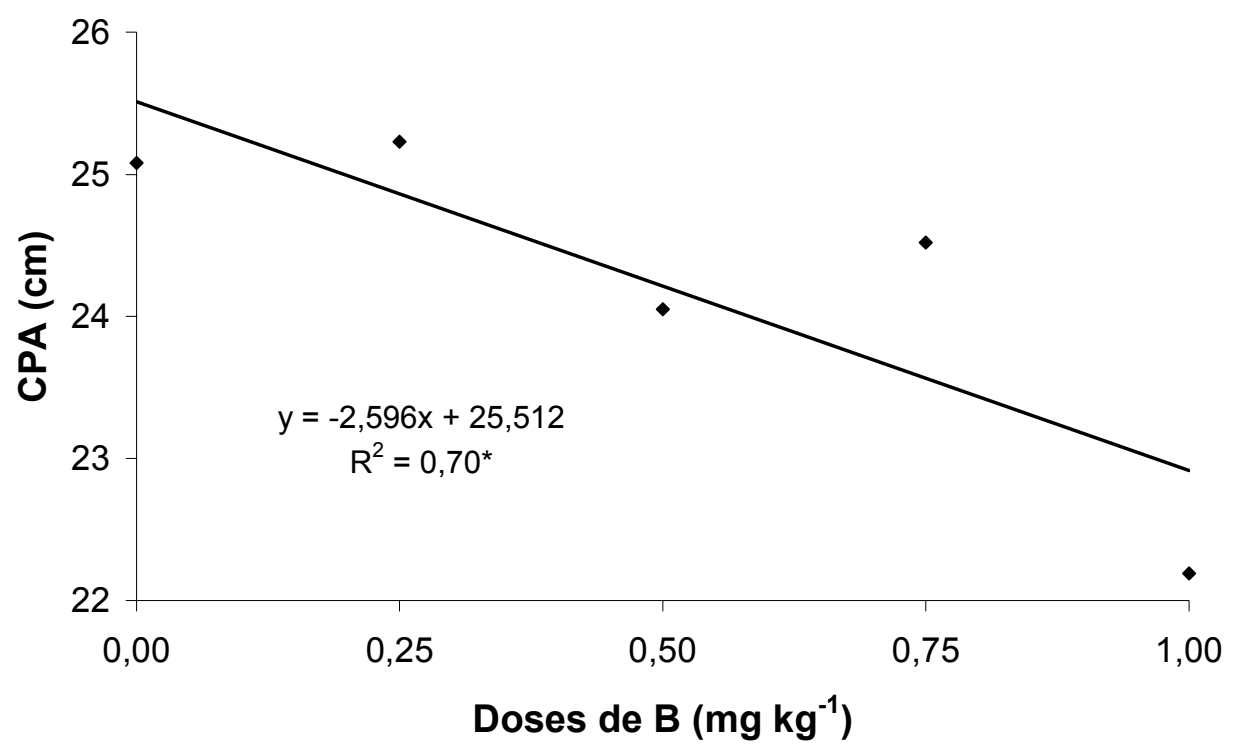

FIGURA 1 - Comprimento da parte aérea do caule (CPA) de muda de mamoneira em função das doses de boro. UFLA, Lavras, 2008. ** Significativo pelo teste $\mathrm{F}$ ao nível de $5 \%$ de probabilidade. 
RODRIGUES, H.C.A. et al. Crescimento de cultivares de mamoneira...

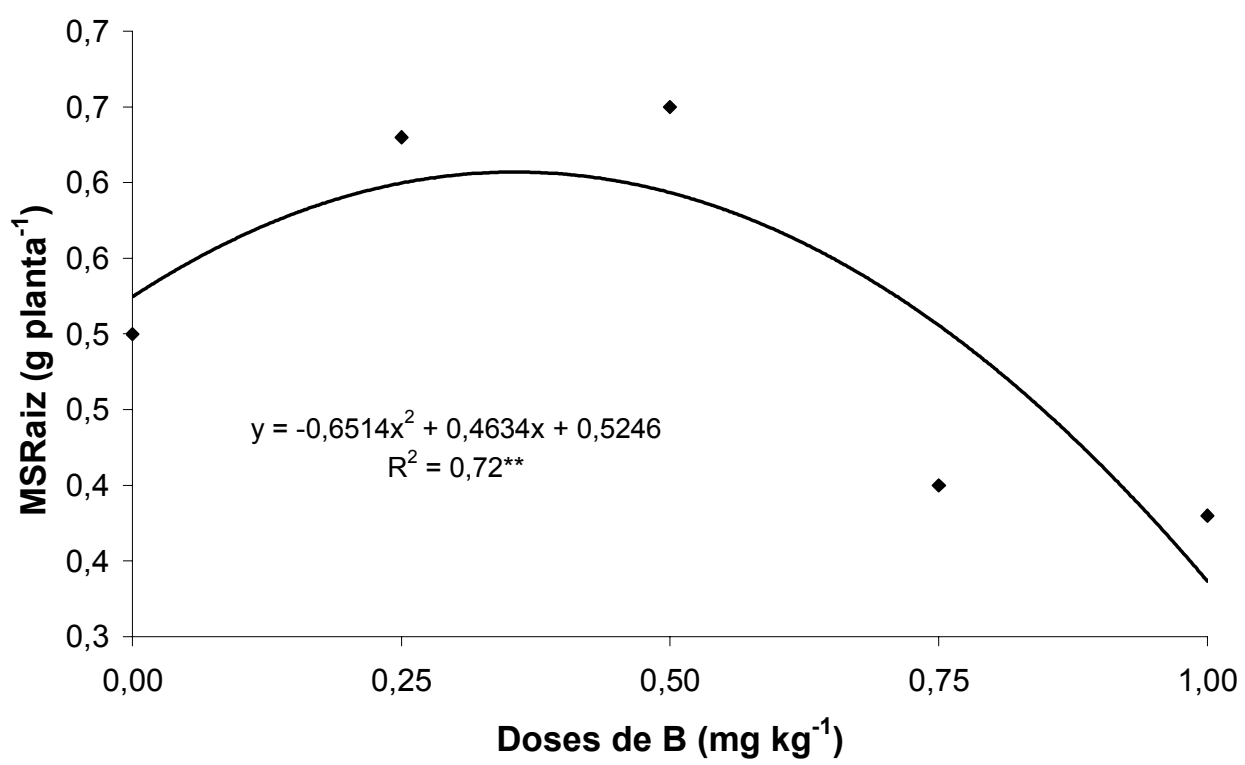

FIGURA 2 - Matéria seca de raiz (MSRaiz) de muda de mamoneira em função das doses de boro. UFLA, Lavras, 2008. ${ }^{* *}$ Significativo pelo teste $\mathrm{F}$ ao nível de $5 \%$ de probabilidade.

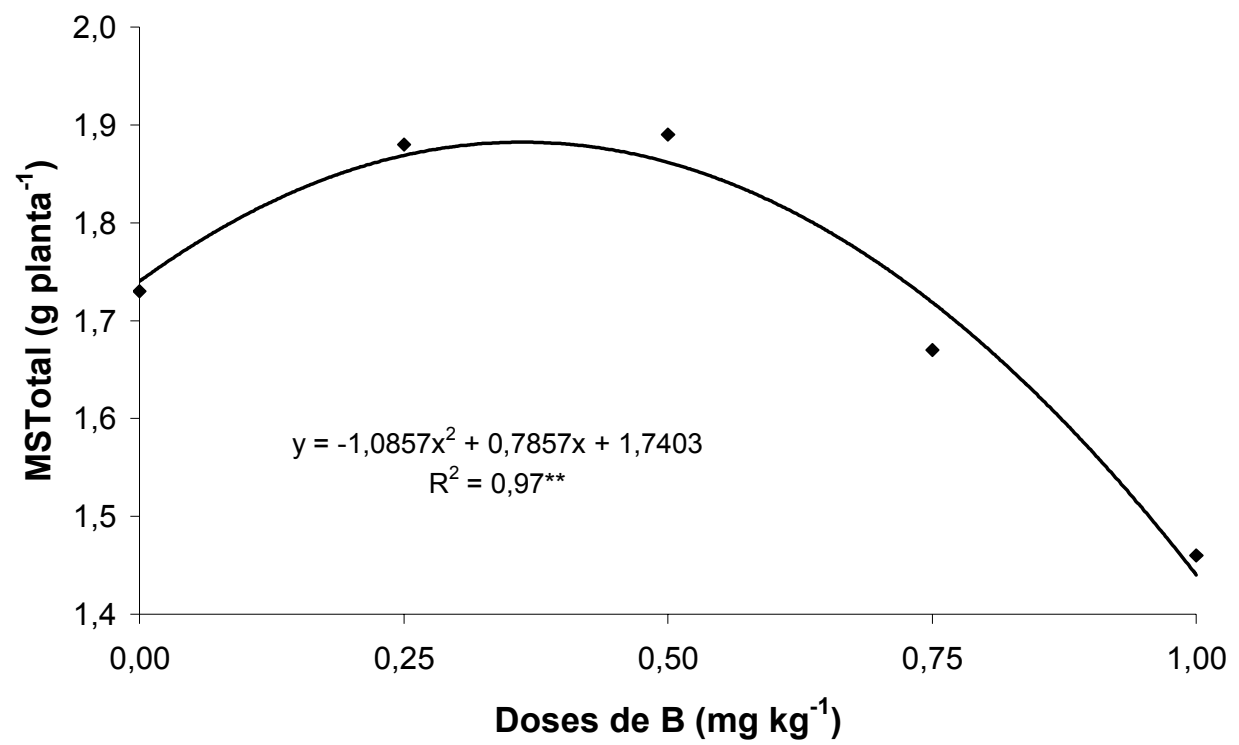

FIGURA 3 - Matéria seca total (MSTotal) de muda de mamoneira em função de doses de boro. UFLA, Lavras, 2008 ** Significativo pelo teste $\mathrm{F}$ ao nível de $1 \%$ de probabilidade.

Silveira et al. (2004) avaliando mudas de eucalipto adubadas com B em casa-de-vegetação concluíram que $E$. saligna é mais sensível à fitotoxidez de B do que E. grandi. Para portaenxerto de seringueira, Moreira et al. (2006) estudando fontes e doses de boro, verificaram que altas doses de boro não afetaram o número de raízes. Prado et al. (2006) determinando níveis críticos de $B$ no solo e mudas de maracujazeiro, verificaram maior desenvolvimento nas plantas crescidas em substrato com $0,5 \mathrm{mg} \mathrm{dm}^{-3}$ de $\mathrm{B}$. Lange et al. (2005) verificaram que a omissão de B na mamoneira cultivar Íris, resultou em deformações no limbo foliar e perda de dominância apical. Eles também constataram que a omissão de $\mathrm{Fe}$ foi a que mais limitou a produção de
MS da mamoneira, seguida pela de $\mathrm{Mn}$ e $\mathrm{B}$.

De acordo com Lima et al. (2004), o início do desenvolvimento da parte aérea da mamoneira é muito lento no primeiro mês após o plantio.

Para um adequado crescimento de mudas de mamoneira até o período de irem para campo a complementação com boro na dose de até $0,36 \mathrm{mg}$ $\mathrm{kg}^{-1}$ no substrato é uma boa opção para se ter mudas de qualidade.

\section{CONCLUSÃO}

A aplicação de doses de até $0,36 \mathrm{mg} \mathrm{kg}^{-1}$ de $B$ no substrato mostrou-se recomendável para o desenvolvimento de mudas de mamoneira nas cultivares AL-Guarani, Mirante 10 e Nordestina. 
RODRIGUES, H.C.A. et al. Crescimento de cultivares de mamoneira...

\section{REFERÊNCIAS}

1. BELTRÃO, N. E. M. et al. Mamona consorciada com feijão visando produção de biodiesel, emprego e renda. Bahia Agrícola, v. 5, n. 2, p. 34-37, 2002.

2. CORRÊA, J. C. et al. Doses de boro e crescimento radicular e da parte aérea de cultivares de arroz de terras altas. Revista Brasileira de Ciência do Solo, v. 30, n. 6, p. 1077-1082, 2006.

3. GOMES, J. M. et al. Parâmetros morfológicos na avaliação da qualidade de mudas de Eucalyptus grandis. Revista Árvore, v. 26, n. 6, p. 655-664, 2002.

4. HADDAD, K. S.; KALDOR, C. J. Effect of parent material, natural available soil boron, and applied boron and lime on the growth and chemical composition of lucerne on some acidic soils of the central Tablelands of New South Wales. Australian Journal of Experimental Agriculture and Animal Husbandry, v. 22, n. 117, p. 317-323, 1982.

5. KAPPES, C.; et al. Doses e épocas de aplicação foliar de boro nas características agronômicas e na qualidade de sementes de soja. Scientia Agraria, v. 9, n. 3, p. 291-297, 2008.

6. LANGE, A. et al. Efeito de deficiência de micronutrientes no estado nutricional da mamoneira cultivar Iris. Pesquisa Agropecuária Brasileira, v. 40, n. 1, p. 61-67, 2005.

7. LIMA, R. L. S. et al. Substratos para produção de mudas de mamona - 4 - bagaço de cana associado a quatro fontes de matéria orgânica. In: Congresso Brasileiro de Mamona, 1, 2004. Campina Grande. Anais... Campina Grande: EMBRAPA, 2004. CD-ROM.

8. MALAVOLTA, E. Manual de química agrícola: adubos e adubação. 1. ed. São Paulo: Agronômica Ceres, 1981. 594 p.

9. MATOH, T. Boron in plant cell walls. Plant and Soil, v. 193, n. 1-2, p. 59-70, 1997.

10. MELHORANÇA, A. L.; STAUT, L. A., RICHETTI, A. Indicações técnicas para a cultura da mamona em Mato Grosso do Sul. Dourados: Embrapa Agropecuária Oeste, 2005. 62 p. (Sistemas de produção, 8).

11. MIRANDA, S. C. et al. Avaliação de substratos alternativos para produção de mudas de alface em bandejas. Seropédica: EMBRAPA Agrobiologia, 1998. 6 p. (Comunicado Técnico, 24).

12. MOREIRA, A. et al. Fontes e doses de boro em porta-enxertos de seringueira. Pesquisa Agropecuária Brasileira, $v$. 41, n. 8, p. 1291-1298, 2006.

13. PRADO, R. M. NATALE, W.; ROZANE, D. E. Níveis críticos de boro no solo e na planta para cultivo de mudas de maracujazeiro-amarelo. Revista Brasileira de Fruticultura, v. 28, n. 2, p. 305-309, 2006.

14. SANTOS, A. R. et al. Boron nutrition and yield of alfafa cultivar crioula in relation to boron supply. Scientia Agricola, v. 61, n. 5, p. 496-500, 2004

15. SAVY FILHO, A.; BANZATO, N. V. Mamona. In: PEDRO JÚNIOR, M. J. et al (Ed.). Instruções agrícolas para o Estado de São Paulo. 2. ed. Campinas: Instituto Agronômico, 1987. p. 231. (Boletim, 200).

16. SHEPETINA, F. A.; SEVAST'YANOVA, L. B. Seed technology. In: MOSCKIM, V. A. (Ed.). Castor. New Delhi: Amerind, 1986. p.175-178.

17. SILVA, D. H. et al. Boron affects the growth and ultrastructure of castor bean plants. Scientia Agricola, v. 65 , n. 6 , p. $659-664,2008$.

18. SILVA, S. D. A. et al. Cultivares. In: MADAIL, J. C. M.; BELARMINO, L. C.; NEUTZLING, D. M. (Ed.). Sistemas de produção da mamona. Pelotas: CNPCT/EMBRAPA, 2007. (Sistemas de Produção, 11).

19. SILVA, S. M. S. et al. Germinação e crescimento inicial de duas cultivares de mamoneira sob estresse salino. Revista Brasileira de Engenharia Agrícola e Ambiental, v. 9, suplemento, p. 347-352, 2005.

20. SILVEIRA, R. L. V. A. et al. Crescimento e sobrevivência de mudas de eucalipto sob doses de boro cultivadas em condições de viveiro e d campo. Ciência e Agrotecnologia, v. 28, n. 2, p. 366-371, 2004.

Recebido em 16/12/2008 Aceito em 17/06/2009 